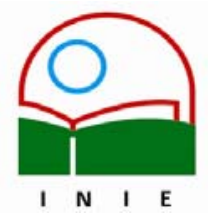

Universidad de Costa Rica

Facultad de Educación

Instituto de Investigación en Educación

ACTUALIDADES INVESTIG ATIVASEN EDUCACION

\title{
CYBERL@B: A PLATFORM FOR LEARNING ENGLISH IN COSTA RICAN PUBLIC HIGH SCHOOLS
}

\author{
CYBERL@B: UNA PLATAFORMA PARA EL APRENDIZAJE DEL INGLES EN LOS \\ COLEGIOS PUBLICOS DE COSTA RICA
}

\begin{abstract}
Allen Quesada Pacheco ${ }^{1}$
"Our language teaching philosophy, method or approach needs to be broadened to encompass new technologies and the inter-relationship between language teaching and computing needs to be carefully explored".
\end{abstract}

(Levy, 1990, p. 5)

\begin{abstract}
This paper covers the design and development of a noncommercial software for learning and practicing English called CyberL@b. It was developed at the School of Modern Languages at the University of Costa Rica. Its target population focuses on $7^{\text {th }}, 8^{\text {th }}$ and $9^{\text {th }}$ graders at six public high schools in diverse urban and rural settings in Costa Rica. CyberL@b uses interactive media resources designed to engage student in learning English within authentic contexts. Cyberlab was designed to create an environment that is unique in fostering the integration of the four language skills (listening, speaking, reading, and writing) through social interactions that are critical in EFL (English as a Foreign Language). An initial needs analysis of the six schools indicated that students considered the following to be important contributors to language learning: conversations with tourists, computer programs and video games, movies, and email of class notes. The implementation of CyberL@b indicates that when students engage in authentic activities relevant to their needs, they become more autonomous and self-directed in their learning. Teachers also adopt more learnercentered methods in their language teaching. On the basis of ongoing development and evaluation, a variety of approaches and technical strategies have been considered to allow students to engage in real-time authentic language learning activities through CyberL@b.
\end{abstract}

Key Words: DIGITAL PLATFORM, COMPUTER-ASSISTED LANGUAGE LEARNING, WEB-BASED LANGUAGE LEARNING, USER INTERFACE, AUTHENTICITY, TECHNOLOGY-ENRICHED LANGUAGE LEARNING, EFL.

Resumen: Este documento describe el diseño y desarrollo de un software no comercial para el aprendizaje y aplicación práctica del inglés llamado CyberL@b. Este software fue diseñado por la Escuela de Lenguas Modernas de la Universidad de Costa Rica y está enfocado para el III Ciclo (sétimo, octavo y noveno grado) en seis escuelas pilotos ubicadas en áreas rurales y urbanas de Costa Rica. CyberL@b utiliza recursos interactivos en línea con el propósito de facilitar el aprendizaje del inglés en contextos auténticos y de crear un ambiente único donde se integran las cuatro habilidades básicas (comprensión auditiva, comunicación oral, lectura comprensiva y comunicación escrita) a través de intercambios sociales que son pertinentes en el aprendizaje de un idioma. Un estudio previo de necesidades indicó que los estudiantes consideran los siguientes recursos como medios muy importantes para el aprendizaje del inglés como lengua extranjera: conversaciones con turistas, uso de programas de computadoras y juegos de videos, películas y correos electrónicos. CyberL@b reconoce estas necesidades y centra su implementación en el hecho de que cuando los estudiantes experimentan el inglés en actividades significativas, el mismo se hace más autónomo y los estudiantes auto-regulan su aprendizaje. Igualmente los docentes adoptan una metodología de enseñanza centrada en los intereses del alumno. Tomando en cuenta el desarrollo y evaluación de CyberL@b, una variedad de métodos y estrategias pedagógicas han sido consideradas con el fin de facilitar el aprendizaje del inglés con actividades significativas y en línea.

Palabras Claves: PLATAFORMA DIGITAL, APRENDIZAJE DE LENGUAS A TRAVÉS DE LA COMPUTADORA, APRENDIZAJE DE IDIOMAS A TRAVÉS DEL INTERNET, INTERFASE DEL USUARIO, APRENDIZAJE DE IDIOMAS A TRAVÉS DE LA TECNOLOGÍA, INGLÉS COMO LENGUA EXTRANJERA

${ }^{1}$ Doctor of Philosophy in Curriculum and Instruction (Enseñanza del Inglés), University of Kansas (KU), E.E.U.U. Master of Arts in TESOL, New York University. Master of Science in Educational Technology, University of Kansas. Catedrático, docente e investigador. Decano de la Facultad de Letras de la Universidad de Costa Rica.

Correo electrónico: alleng@cariari.ucr.ac.cr

Artículo recibido: 20 de julio, 2006

Aprobado: 20 de noviembre, 2006 


\section{Introduction}

A Website and a CD-ROM called CyberL@b was recently developed for the teaching and learning of English as a Foreign Language (EFL), associated with the English language learning curriculum for 7th, 8th and 9th grades in Costa Rica. This curriculum is currently being piloted at six high schools in diverse locations across the country. The CyberL@b project uses interactive media resources that are designed to engage students in learning English within authentic contexts that are relevant to the students' lives. It also examines the learning contexts and changing roles of both teachers and students when using the software.

Technology can serve as a powerful resource for guiding constructive learning activities to advance English as a Foreign Language Learning (EFL) in secondary schools, especially if it is based on the national curriculum of the Ministry of Education. CyberL@b fulfills this necessity by adopting a Computer-Assisted Language Learning (CALL) approach that is guided by the need to enhance authentic social interaction among Costa Rican students as a critical component of the EFL learning environment.

Edgert, Chao \& Hanson Smith (1999) have explained that certain conditions should be met to reach optimal levels of language learning environments, for example, learners should be given opportunities to interact and negotiate meaning, and they should be both involved in authentic tasks and able to interact with an authentic audience. These scholars claim that optimal levels are also reached if learners are exposed to and encouraged to engage in the production of varied and creative language, especially when they have enough time and feedback to formulate ideas. Learners should also be challenged cognitively and motivated to achieve high levels of proficiency within stress-free environments. Other positive effects in this process deal with having learners take responsibility for their own learning. Thus, learners become autonomous in the development of skills, tasks, and strategies that will enable them to practice purposely the new language (Egbert \& Hanson-Smith, 1999).

Under the aforementioned guiding principles, the CyberL@b resources and curriculum were designed as an interactive on-line EFL program that integrates listening, speaking, reading and writing with a specific focus on authentic cross-curricular content. The initial implementation of CyberL@b was designed for 7th, 8th and 9th grades of the public schools in Costa Rica. The components of the different units of CyberL@b acknowledge public school standards of the official English Language program for these three levels.

The CyberL@b design seeks to provide a user interface that becomes transparent to learning (Shneiderman, 1998) with a consistent look and feel that uses standardized naming schemes, graphics, orientation, navigation and other user interface elements. The use of grade 
appropriate language for functional elements is especially critical in EFL online resources. Terms must be clearly defined, highlighted, punctuated and used consistently. The Internet and related technologies are evolving rapidly worldwide, and it is becoming more critical to adhere to international standards including relevant tagging procedures established by the World Wide Web Consortium (W3C), Advanced Distributed Learning Group (ADL SCORM), IEEE Learning Technology Group and CAST's Bobby guidelines for accessibility (Aust \& Isaacson, 2005). CyberL@b is designed to personalize the interface for different categories of learners. For example, a simple implementation of personalized design is to use different colored platforms for each grade level (see pictures below) and the six-sequenced cross-curricular topic-based components that integrate authentic content with the four basic skills in English (Log On, Turn It Up, System Tools, Scan It, Type it Up, and Log Off).

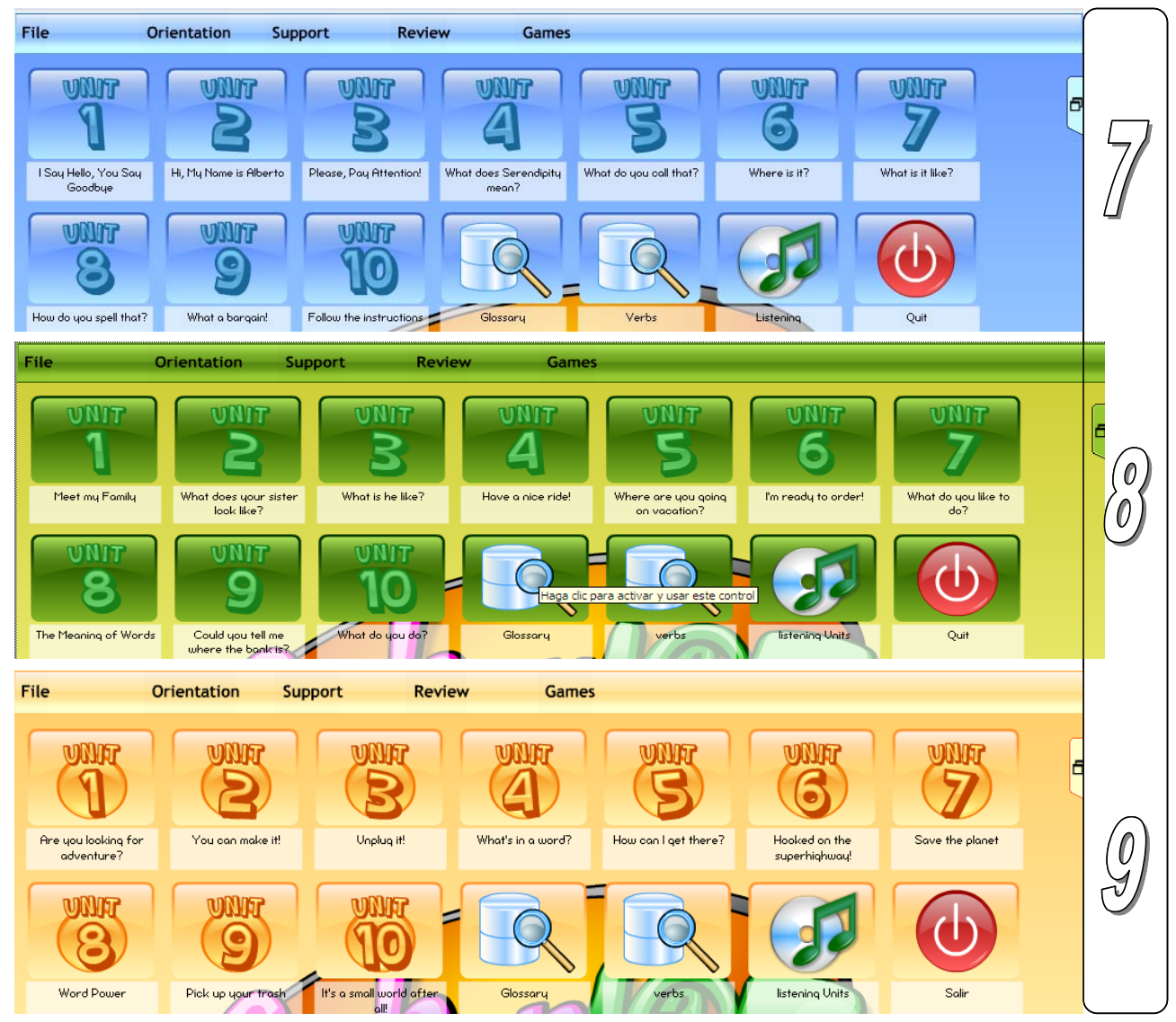

Snapshot of $7^{\text {th }}, 8^{\text {th }}$, and $9^{\text {th }}$ grade platforms

The following section examines the theoretical foundation for the use and implementation of CyberL@b in the teaching of English as a Second or Foreign Language. It reviews the 
implications of Web-based CALL and its connection with CyberL@b. The paper also describes CyberL@b's main components which illustrate the structure, sequencing and pacing of each of the units.

\section{Ministry of Education Policies in TEFL}

The Education Law and the Educational Policy "Towards the 21st Century" in Costa Rica confirms the fact that in order to help Costa Rican students face life and work situations, they require an average command of English in order to participate actively into the challenges of the global economy for the benefit of the country. For this reason, English as a Foreign Language has been incorporated in all four levels of learning (I Cycle, II Cycle, III Cycle, and Educación Diversificada). The Ministry of Public Education (MEP-Spanish acronyms) has explained in the official English Programs of the country that the purposes of English Language Teaching in Costa Rican Educational System should respond to the following needs:

1. To offer students a second language that can enable them to communicate within a broader social-economic context in and outside Costa Rica.

2. To give students a tool to directly access scientific, technological and humanistic information and, in this way expand their knowledge of the world. (Campos, et. al, 2003)

Additionally, the MEP has explained that these needs should be complemented with the following objectives in classroom settings:

- develop the ability to communicate for practical purposes;

- frame a sound basis of the language skills, and attitudes required for further study, work and leisure;

- $\quad$ offer insights into the culture and civilization of English speaking countries;

- $\quad$ develop an awareness of the nature of language and language learning;

- $\quad$ incite enjoyment and intellectual stimulation;

- $\quad$ encourage positive attitudes towards foreign languages and cultures;

- $\quad$ promote cognitive skills like application analysis, memorization, inferring;

- $\quad$ develop students' understanding of themselves and their own culture. (Campos, et. al, 2003)

According to the MEP, the study of second languages contributes to enrich the school curriculum because of the following reasons:

- It provides a combination of linguistic skills both physical and intellectual with personal and social development; 
- It offers better opportunities to develop oral and written communication skills;

- It promotes valuable study skills such predicting, selecting, comparing, and interpreting information and memorizing, and focusing on general and detailed meaning in listening and speaking;

- It helps develop the learners' awareness of cross-curricular at the time that builds on the four communication skills (Campos, et. al, 2003)

In Costa Rica, English is learned as a foreign language. The environment that surrounds the learner is not an English-speaking environment. Thus, students, when learning English, can only experience it in classroom settings. When they leave school, they spend most of their time using their native language (Spanish). In order to accomplish the goals of the Ministry of Education, new and innovative methodologies have to be implemented to facilitate the practice of English for the growth and development of our country. Trying to respond to the educational needs of our country, a proposal for the design of a digital platform was presented to the Ministry of Education, which recommends Web-based Computer-Assisted Language Learning for the third cycle of high school studies $\left(7^{\text {th }}, 8^{\text {th }}, 9^{\text {th }}\right.$ grades $)$ as a means to complement the official English Program. This official English Program requires students to communicate in the four language skills in the following topics:

\section{$7^{\circ}$ LEVEL}

1. Exchange greetings, leave takings and introductions

2. Identification of oneself to others

3. Directions or instructions

4. How a dictionary is organized

5. Classroom objects

6. Location of people and objects

7. Description of something

8. Use a dictionary to spell words

9. Goods and services

10. Instructions

\section{$8^{\circ}$ LEVEL}

1. Identification of family members and partner's relatives

2. Description of people's physical appearance

3. Comparison of people's physical features and personality traits

4. Meaning of words according to a given context

5. Relevant characteristics of the means of transportation available 
6. Personal travel plans

7. Acceptance and refusal of goods and services

8. Likes, dislikes and preferences

9. Grammatical functions of words

10. Give and follow directions

11. Occupations

$9 \circ$ LEVEL

1. Sports and leisure activities

2. Life and achievements of famous athletes and musicians

3. Operation of electronic equipment

4. Roots, suffixes and prefixes

5. Transportation, quality, rentability and use

6. Computers and technology today in our lives

7. Natural resources and the promotions of conservation

8. Specific information of words in a given context (registers),

9. Causes, effects, and prevention of environmental pollution (Campos, et.al)

CyberL@b includes all of the topics which are required to teach and learn English for seventh, eighth, and ninth grades. Its intention is not only to incorporate these topics into a digital platform, but also to integrate a cross-curriculum topic-based program fostering the teaching and learning of the four skills: listening, speaking, reading and writing. Its design incorporates Web-based Computer-Assisted Language Learning as a new trend that promotes learner-centeredness in the EFL classroom.

\section{Features of Web-based CALL}

Computer-Assisted Language Learning (CALL) is an approach to language teaching and learning in which computer technology is used as an aid to the presentation, reinforcement and assessment of language learning on an interactive basis (Egbert and Hanson-Smith, 1999). Integrative CALL heightens the development of two technological features in language learning: multimedia computers and the Internet. The issue that promotes CALL environments is the need to incorporate a globalized learner into society; one that is able to communicate across languages and cultures. Web-based CALL meets language learning objectives and exploits second language learners' potential by leading them to "learning by doing" in authentic English language learning contexts.

Since the emergence of the Communicative Approach, the need to meet authentic and meaningful EFL settings has increased. Likewise, bringing to class artificially contextualized 
environments has decreased. In search for this authenticity, Web-based learning has gained popularity and is exploited as a medium for student-centered, task-based and collaborative learning.

The developers of Learning Generations (Aust, et.al., 2005) as well as other technology-enriched approaches to learning like those proposed by Duhaney (2001) have noted that the advent of the Internet and new digital technologies are rapidly changing the role of the teacher and the nature of learning. The classroom teacher is no longer viewed as the repository of knowledge but as a facilitator who guides students towards self-directed learning through relevant digital environments. Current generation teachers serve to assist students in organizing learning activities where students construct understandings around authentic and meaningful collaborative experiences. Jackson (2006) highlighted three different learning contexts that occur when students begin interacting with current learning technologies such as self-study (asynchronous directed study), instructor-led events (synchronous "live, real-time" learning), and small group collaboration.

\subsection{Self-Study Learning}

Jackson (2006) has explained that self-study learning experiences rely on some structured plan that directs the learner through learning experiences without real-time interaction from an instructor. CD-ROM based tutorials, paper-based correspondence, and "Click-to-Learn" Web-based systems are implemented and may be supplemented by asynchronous interaction with the instructor. Learning foundations are created in this mode through the implementation of learning strategies such as contextual background, factual knowledge, course readings, skills practice, homework, and hands-on activities that allow learners to reach levels of application and assessment.

\subsection{Instructor-led Learning}

Instructor-led learning events are distinguished from directed study in that there is some commonly shared experience or event. These events generally occur "in real-time with highly interactive and structurally dynamically characteristics led by the instructor" (Jackson, 2006, p. 3). It is characterized by certain capabilities:

a. awareness: A learner is aware that other members are on-line.

b. shared objects: Both instructor and learners view learning content simultaneously but in an interactive way, where learners share live information and application. 
c. instructor-led or instructor-moderated communication: Selective interaction between learners and/or instructor occur, but the instructor controls and guides the flow of interaction. It allows two modes: broadcast model where the teacher delivers instructions with little interaction from the students, and dialog model where the instructor creates a highly interactive learning experience and dynamically monitors and adjusts the flow of dialog/learning.

\subsection{Small Group Collaboration}

The third learning context in Web-based CALL is small group collaboration. This category embraces "learning methods dependent on learner-learner interaction rather than learner-content interaction, and includes models such as constructivism, action learning, conversational learning" (Jackson, 2006, p. 4). Small study groups work on team projects and learn cooperative teamwork skills. It integrates both asynchronous (self-study) and synchronous (instructor-led) tools. This learning context increases learners' autonomy in the process of learning a language and decreases the time required for the instructor to administer and structure the language program. One important feature of this learning context is the peer-to-peer communication through projects, simulations, hands-on experiences/activities, instructor-facilitated group study sessions, among others.

Indeed Web-based Computer-Assisted Language Learning calls for a shifting role of traditional classroom hierarchy to a more balanced relationship between teachers and their students (Qiming, 2002, p. 3).

The teacher is no longer the person who tells the students what they have to do and how to go about it. He or she helps individual students achieve the most they can and can only do this if the basis of the teacher-student relationship is far more balanced than in the traditional classroom.

Web-based CALL requires self-study (for autonomous learning), teacher-led instruction (for organization, monitoring, administering), and small-group discussions (for interactivity). It also allows learners to control selection, sequencing and the pace of learning, and it allows teachers to take the role of facilitators/coaches by providing a flexible learning environment which can be self-paced and individualized, group-oriented, synchronous and asynchronous (Qiming, 2002). 


\section{CyberL@b and Web-based CALL}

CyberL@b is a digital platform that incorporates Web-based learning as a means for facilitating the practice of English as a foreign language. This integrated cross-curriculum topic-based program allows on-line users to grow in the English language by immersing learners into the topics found in the National English Curriculum of the Ministry of Education with controlled, semi-controlled and communicative tasks (see http://lemo.le.ucr.ac.cr). As students work with CyberL@b, they are led towards critical thinking, problem-solving experiences, and hands-on projects, providing authenticity and meaningfulness to learning English. The uniqueness of its components describes its capabilities. (See picture below)

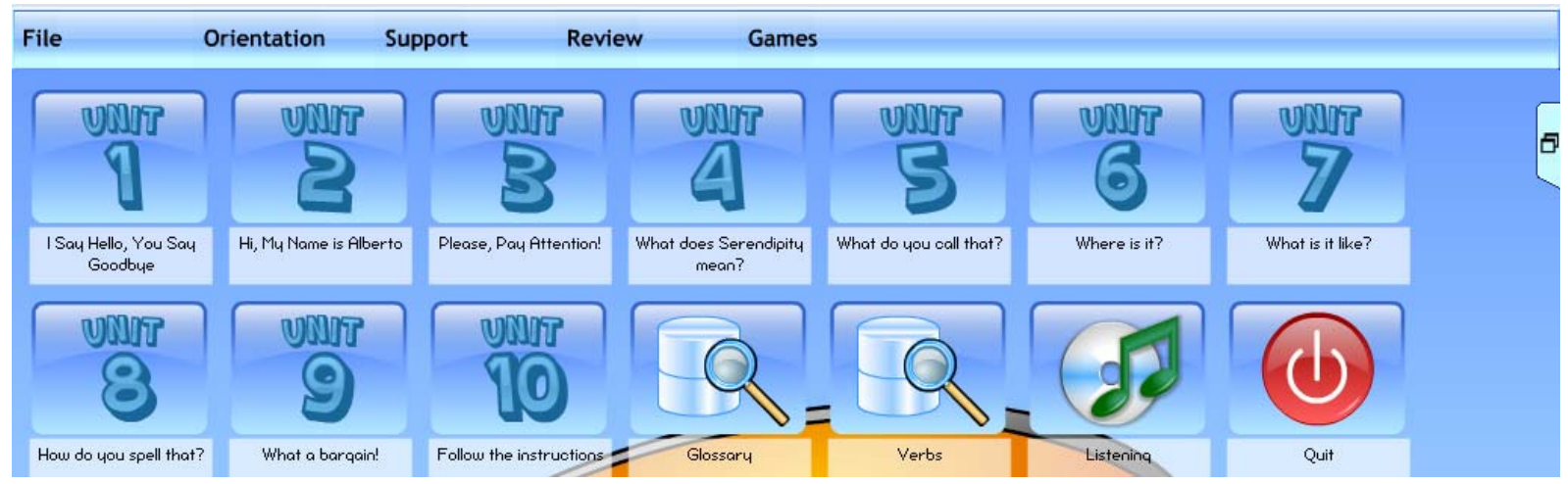

Cyberlab snapshot for Seventh Graders

\subsection{Description of the components of each unit}

Each unit consists of six teaching components dealing with the integration of the four macro skills (listening, speaking, reading and writing) and micro language skills (grammar, pronunciation, culture and vocabulary). These are described below: 


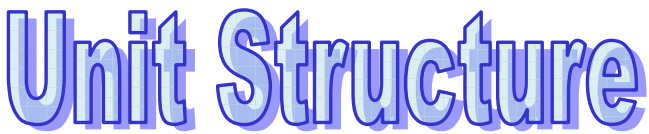

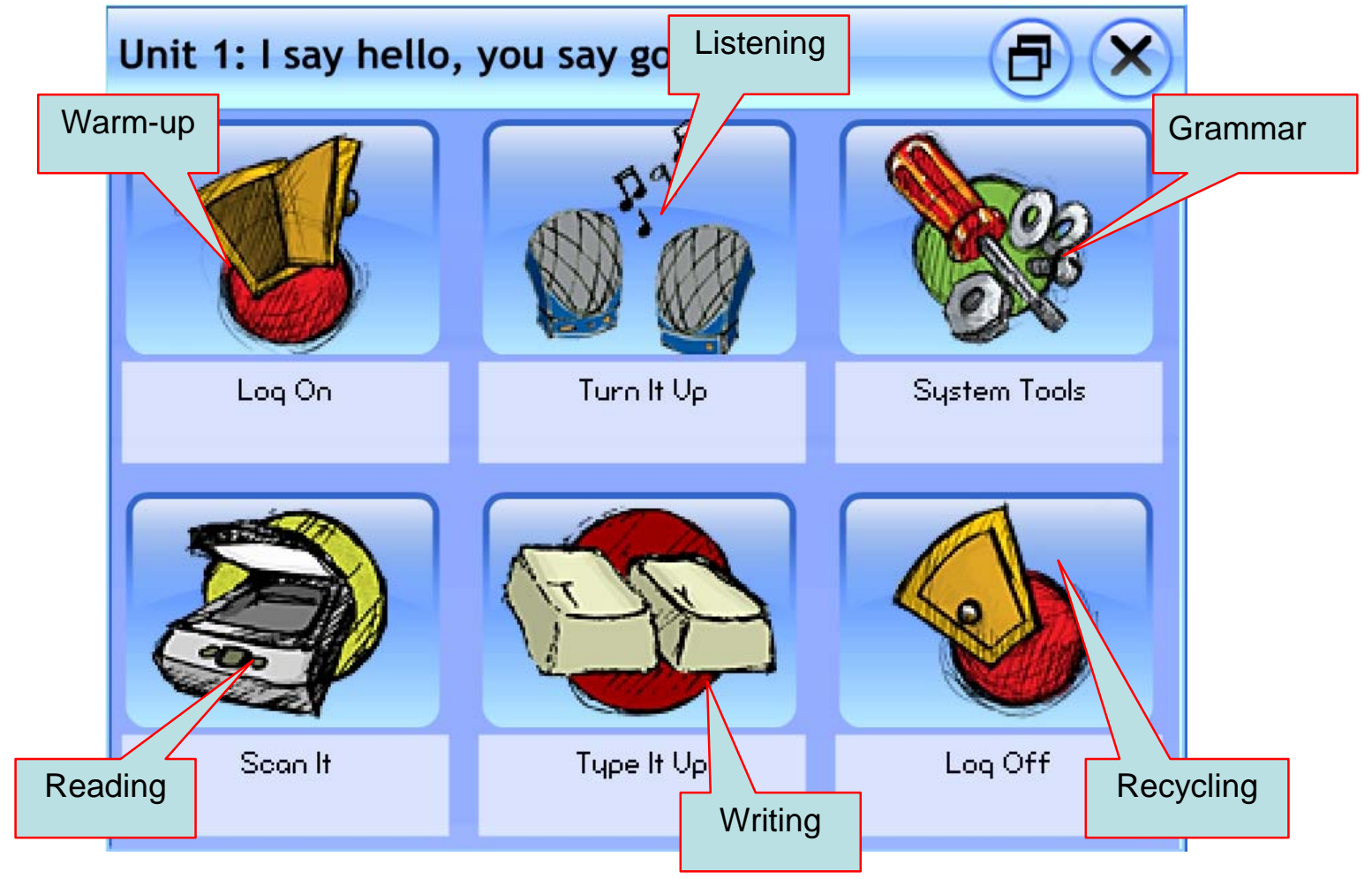

\subsubsection{Log on (Schema Activation)}

$\log$ On is the opening to each of the units. It is divided into four sections: goals, vocabulary, warm-up and your turn.

- In each unit the "goals" are specified from the beginning so that EFL learners are aware of the objectives they have to accomplish in the language and the content.

- The "vocabulary" section allows them to match their prior knowledge of the topics with the new vocabulary they will meet in the units with an activity.

- The "warm-up" section reinforces the vocabulary they have already practiced with a supplementary task.

- In "your turn", students are able to relate the topic to their daily life experiences. 


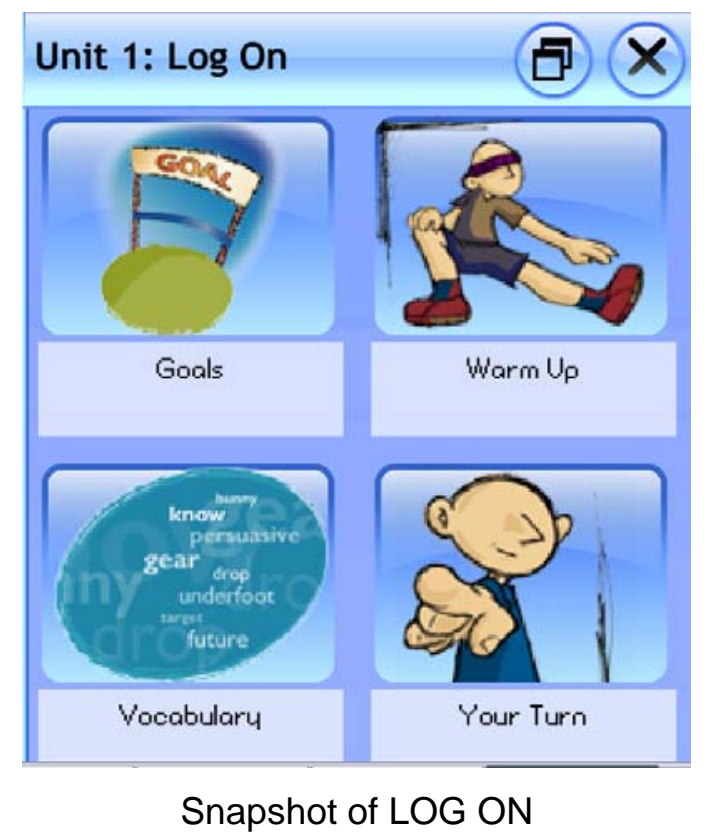

\subsubsection{Turn it Up (Listening)}

Turn It Up deals with the listening skill. It is composed of three parts: pre-listening, while listening and post-listening.

- Pre-listening prepares students to listening, involving them in several learning strategies. Students are engaged both in top-down and bottom-up strategies such as listening for the main idea, predicting, drawing inferences, summarizing, activating background knowledge of the topic, listening for specific details, recognizing parts of speech, recognizing wordorder patterns, among others.

- While-listening involves listening to content in order to get a global understanding of the information provided to promote proficiency in listening skills. Students are expected to complete spaces, answer questions, and do multiple choice activities, among others.

- Post-listening relates the information they have previously listened to their everyday life by working in pair or group work activities. Students are engaged in interviews, surveys, question-and-answer tasks, and so on.

Turn it Up also deals with pronunciation, intonation and stress activities to give learners opportunities for improving their use of the English language. 


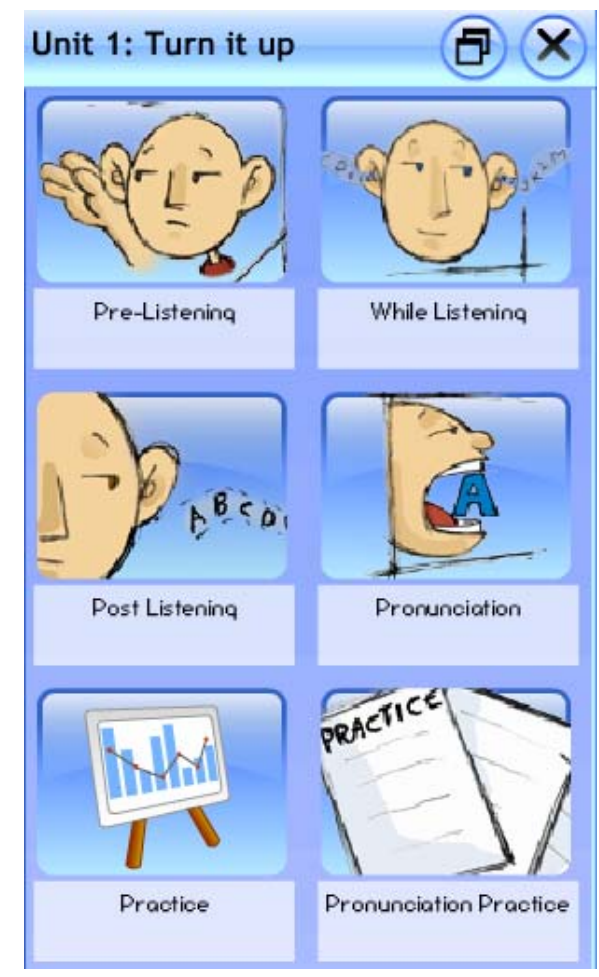

Snapshot of Turn It Up

\subsubsection{System Tools (Grammar)}

System Tools integrates structure through easy-to-remember rules of thumb which provide a solid starting point towards accuracy and show how grammar really works in context. On-line learners will experience grammar in simple rules, rules needed for effective communication. System tools simplifies the grammar for learners and learners "grow their grammar" with practices and activities as they work on the different units. It works as follows:

- First, learners are exposed to the structure inductively and deductively. That is, they experience the contexts where the rule is used through the description of pictures.

- Then the rule is shown in a simple way and students are engaged in three supplementary practices.

- After that, students use the rule in real contexts in "Your Turn" by doing very short investigations, quick surveys, or question-and-answer activities related to their daily life activities. 


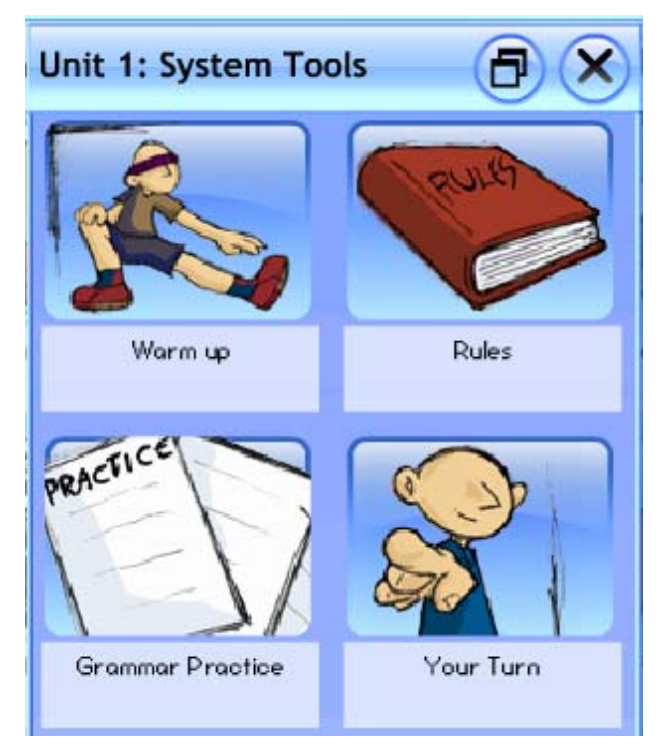

Snapshot of System Tools

\subsubsection{Scan It (Reading)}

Scan It develops learners' reading skills. It is divided into pre-reading, while-reading and post-reading through the top-down processing to reading.

- The pre-reading stage is an "engaging" stage where the students' interest is aroused, and a connection to their prior knowledge of the topic is triggered. This is done through opinion tolls, prediction strategies, activation of background knowledge, such as brainstorming, semantic mapping, class discussions, pre-questions, and so on.

- In the while-reading stage, students gain deeper insights on reading skills through skimming, scanning, think-aloud, inferring, visualizing, restating, re-reading, drawing conclusions, clarifying, using contextual clues, question-answer-relationship (QAR), among others.

- The post-reading stage relates the reading to the students' real-life experiences by making connections to their daily life activities. In this stage, students are engaged on postreading surveys, investigations, QAR, or other authentic supplementary activities to establish experiential reciprocity to the topic been read. 


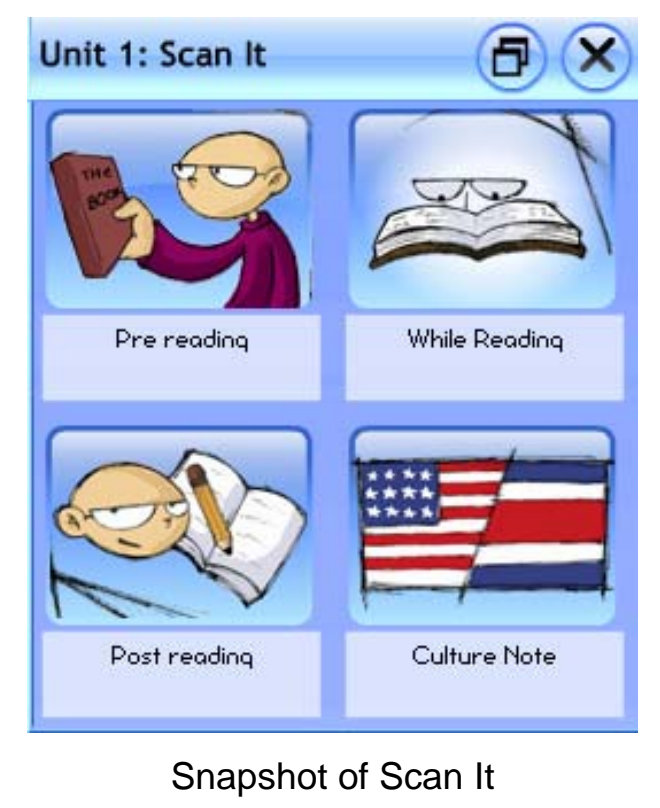

\subsubsection{Type it Up (Writing)}

Type It Up involves three stages: pre-writing, while-writing, and post-writing.

- In the "Prewriting" stage, learners are involved in a series of different methods to generate ideas for their written texts, like for example, brainstorming, listing, clustering, sketching, peer discussion, questioning, outlining, free-writing, reading, opinion charts, graphic organizers, and so on. This stage prepares learners to organize their thoughts, think more clearly and begin to put the information in paper.

- Throughout the "while-writing" stage, learners activate their writing skills through planning, using structures to organize writing, drafting, and putting ideas down. This stage includes writing short paragraphs with attention-getting titles, topic sentences, supporting details and concluding statements. In short, learners are guided to the process of writing and lots of assessment is involved.

- The "post-writing" stage includes strategies such as polishing for final draft, sharing for portfolio assessment, assessing and evaluating both process and product. To do this, learners are engaged in collaborating techniques that include discussions, conversations, paper exchanging, among others with both their peers and teacher. 


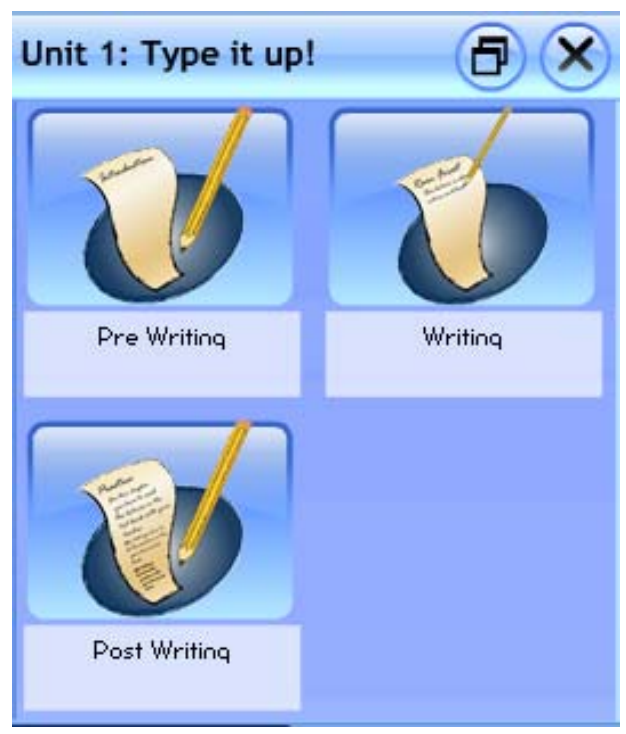

Snapshot of Type It Up

\subsubsection{Log Off (Review of Unit)}

Log Off integrates listening, speaking, reading and writing skills by linking the topic of the unit to a real-life situation through cooperative learning. Log Off comprises three stages: team project, searching the web and self-assessment.

- The team project establishes a bond between the topic of the unit and a situation encountered in the learners' everyday life. Students are given clear objectives of the team project and they are organized into groups with roles that include leader, secretary, designer, and assistant. This step-by-step team project is assessed, and the stage ends with an oral presentation of the project to class, to the school or to the community.

- Searching the Web is part of the stages of logging off too. Here learners have the opportunity to be engaged in web-based learning following the integrative CALL approach. In this section, learners have the opportunity to search and work through several web links and engage in listening, speaking, reading and writing activities. This stage serves as an integration of the skills and strategies they have accomplished throughout the unit.

- Finally, Self-Assessment helps learners reflect on what they have accomplished throughout the unit by identifying their areas of success in using the communicative skills such as listening, speaking, reading and writing. In other words, self-assessment promotes self-evaluation on skills and strategy training, and promotes a sense of 
reflection on how students have progressed in the language and how these new skills and strategies will help them in their everyday life activities.

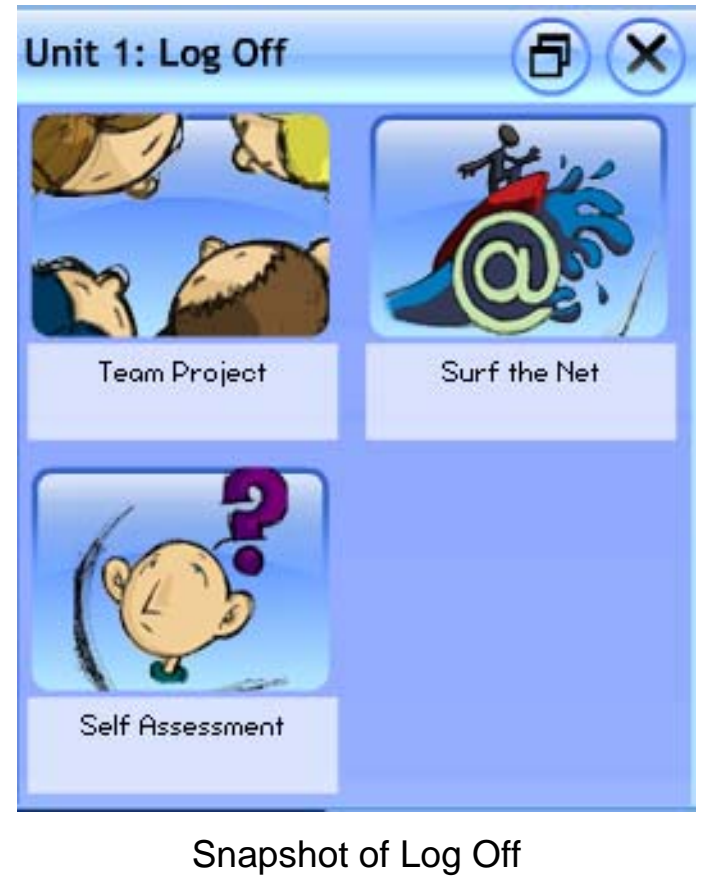

\subsection{Culture Notes and Pair Work Activities}

Culture Notes and Pair Work Activities are supplementary practices at the end of each of the units. It includes short readings on culture snaps about the topics discussed in the unit, involving students in interactive activities. This section is also composed of a pairwork activity or an information-gap activity that allows learners to practice collaborative interactive skills. In each of these information-gap activities, each member needs the information that the other peer possesses.

To complete his or her information, the use of social strategies are required such as asking questions, asking for clarification, asking for correction, cooperating with peers, developing understanding, negotiating meaning, among others.

At the end of this section, learners are able to complement their knowledge of the topic with a glossary that enables them to discuss with peers the meaning and use of the words encountered through the entire unit. 


\subsection{Speaking skill}

Speaking is the most important skill in this digital platform. It is integrated with listening, reading and writing components in every unit. Speaking is activated in all three dimensions of each language skill as a pre, during or post task. Students are engaged in discussions, questioning, opinion exchange, etc., when they activate their prior knowledge on the content of each unit. To do this, they have to interact or exchange ideas with their classmates about different topics. Students are also involved in speaking every time they work on the information-gap activities that are found in the supplementary activities described in 4.2 section of this paper (Culture notes and Pair Work activities) by triggering their social strategies.

Added to this, in the section "Your Turn" of every component, students practice the speaking skill with hands-on projects, simulations, role-plays, question-and-answer sessions, surveys, interviews, among others. Interaction is also activated at the end of each unit with the final project. In order to accomplish the objectives of these final projects, learners should engage in authentic conversations with members of the community in most of the cases. These face-to-face hands-on projects demand lots of negotiation of meaning in its development and in its oral presentation.

CyberL@b also complements each on-line unit with resources for the teacher to work with: a textbook that pictures all of the activities that are found on-line and a teacher's resource book or teacher's guide that suggests what should be done as a pre- or postactivity for each of the components (log-on, turn it up, system tools, and so forth). Most of these extra activities enhance a communicative methodology allowing interaction at all times.

\subsection{Review Units}

Review Units are unit-specific, student-directed activities that comprise skills and structure of every three units. Each grade (7th, 8th, and 9th) has three review units. These review units include exercises with interesting tasks that are authentic, creative, and interactive. The interconnection of the four skills is exploited in the review units.

As a whole, CyberL@b includes receptive, active and interactive hands-on activities. Receptive activities allow foreign language learners to gather information from a series of sources: face-to-face surveys and interviews, readings, vocabulary-building exercises, project-based observations of the community, personal experiences, internet sources, and listening activities, among others. 
Active practices promote authenticity by encouraging learners to address an authentic audience in the production of short writings, comments on observations, exchange of information from interviews, simulations of daily activities, answering on-line quizzes, completion of questionnaires, etc.

Last, but not least, in interactive activities, learners are both receiving and sending information in task-based and project-based activities that require collaboration and team work. Interaction allows learners to use the English language in meaningful contexts, promoting a sense of ownership and strategic investment as they experience their progress in the language. At this stage, learners using CyberL@b can become risk-takers with added motivation and self-confidence.

In sum, the novelty of CyberL@b is that this digital platform tries to picture the reality of the Costa Rican English Language Curriculum as well as its culture and its people, taking into account the needs and interests of Costa Rican students who are learning English. In other words, all ten units for the three levels $\left(7^{\text {th }}, 8^{\text {th }}, 9^{\text {th }}\right)$ are directly correlated with the topics and contents required by the Ministry of Education. The uniqueness of this interconnection can be narrowed into the following characteristics:

- The topics are practiced meaningfully with the integration of the four skills (skillsbased approach)

- The tasks students develop in the digital platform simulate everyday tasks (taskbased approach)

- The classroom activities shift away from the classroom practices of short, isolated, teacher-centered lessons and instead emphasize learning activities that are longterm, interdisciplinary, student-centered, and integrated with real world issues and practices. Students apply and integrate the content of different subject areas at authentic moments in the production process, instead of in isolation or in an artificial setting. (project-based approach).

- The content required by the Ministry of Education is blended into Web-based instruction strategies such as conversing, discussing, mentoring, questioning, supporting a partner, debating, impersonating, role-playing, sharing data, analyzing, developing products, traveling virtually, organizing, synthesizing online information, exploring real-world problems, accessing tutorials with on-line exercises, quizzes, questions, tasks, among others (Web-based approach) 
As part of the creation of Cybel@b, a needs analysis study was carried out in the six Costa Rican high schools participating in the piloted research.

\section{Needs Analysis of Costa Rican High School Students}

\subsection{Method}

This is a qualitative study that describes the needs and interests of students regarding the importance of the four skills (listening, speaking, reading, and writing) for the acquisition of English as a Foreign Language.

\subsubsection{Subjects}

The participants of the study were 416 students from six Costa Rican high schools. Fifty two percent (52\%) of the subjects were female and $48 \%$ were male. $93 \%$ of the students come from public high schools. Three of the pilot public high schools involved in this survey were from rural areas (Pejivaye, Sinai and Florencia), and three from urban areas (Palmares, Cot 8, and Liceo del Este). All of the students are enrolled in seventh, eighth or ninth grades. (See table 1)

Table 1

Number of Students who participated in the Qualitative Study on the Importance of Four skills in Learning English as a Foreign Language

\begin{tabular}{|c|c|c|c|}
\hline \multirow[b]{2}{*}{ High Schools } & \multicolumn{3}{|c|}{ Levels/ grades } \\
\hline & Seventh & Eighth & Ninth \\
\hline Pejivaye .... & $\ldots 13 .$. & $20 \ldots$ & .23 \\
\hline Sinai & 28 & 16 & 14 \\
\hline Florencia. & .27. & $48 .$. & .21 \\
\hline Palmares & 31 & 30 & 38 \\
\hline Cot $8 \ldots \ldots \ldots \ldots$ & $.13 \ldots$ & $17 \ldots$ & .23 \\
\hline Liceo del Este & 18 & 18 & 18 \\
\hline
\end{tabular}

\subsubsection{Description of the Instrument}

The instrument was divided into five sections. The first four sections asked the subjects to rate the importance of the different resources used for learning listening, speaking, reading and writing of English as a Foreign Language (whether the resources were important or not for practicing English). 
In section $A$, subjects were asked to rate the following reading resources to practice English: textbooks, dictionaries, magazines, newspapers, Internet pages, electronic mails, catalogues, announcements, subtitles in English from movies, computer programs, and video games.

Regarding resources for practicing listening (section $\mathrm{B}$ ), subjects rated the following: movies, songs, TV Cable, radio, native speakers of English, the English teacher, cassettes, telephone conversations, instructions, and conferences.

The following resources appeared in section C for practicing writing: class notes, homework, paragraphs, forms, after-class reports, electronic mails, tests and quizzes, notes to classmates, posters or others.

For speaking (section D), the following resources were rated in order of importance: conversations with classmates, with the teacher, with friends, with tourists, with relatives, on the phone, oral presentations, and interviews.

On Section E, subjects had to choose the skill they needed the most for learning English and explain why.

\subsection{Needs Analysis Results}

According to the students of rural high schools, (Florencia, Sinaí, and Pejivaye) the Internet, computer programs, textbooks and dictionaries are the resources that help the most in practicing the reading skill.

In regards to listening, $64.36 \%$ of the subjects believe that teacher's instructions, the teacher him/herself, native speakers of English, and movies are the most important resources. For $55.35 \%$ of the subjects, class notes, electronic mails, tests and homework are very useful for writing skills. In regards to speaking, $55.82 \%$ of the students think that having conversations with tourists, with friends, with classmates, with the teacher, and having oral presentations in class are the most important resources.

In general, these subjects agreed that the most important resources for practicing listening, speaking, reading and writing are computer programs, video games, reading Internet web pages, listening to the teacher, listening to movies, tests, class notes, talking to tourists, native speakers, and the teacher. In regards to the skills, these high schools agreed that the most important skill is speaking. (See Table 2) 
Table 2

Important Resources that Facilitate Listening, Speaking, Reading and Writing according to Rural High Schools in Costa Rica

\begin{tabular}{|c|c|}
\hline Resources & Highest Scores \\
\hline Read computer programs and video games & ......61.32\% \\
\hline Read web-pages & $60.79 \%$ \\
\hline Listen to the English teacher.. & $65.59 \%$ \\
\hline Listen to movies recorded in English & $63.13 \%$ \\
\hline 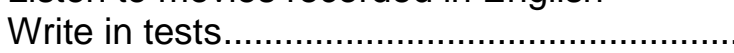 & $.57 .02 \%$ \\
\hline Write class notes & $53.69 \%$ \\
\hline Conversations with the English teacher ......... & .....57.83\% \\
\hline Conversations with tourists & $53.81 \%$ \\
\hline
\end{tabular}

Similarly, $65.9 \%$ of the students from urban high schools, (Palmares, Liceo del Este and Liceo de Cot) answered that the most important resources for reading skills are the Internet web pages, computer programs and video games, and electronic mails; in regards to listening, more than $60 \%$ believed that movies, TV cable, and the teacher are important. For $54 \%$ of the subjects, electronic mail, class notes, and tests are the most important resources for writing skills. In regards to speaking, $60.9 \%$ agreed that having conversations in class, with tourists, with friends, with the teacher, and delivering oral presentations in class are very important resources.

For the students of the urban high schools, the most useful resources for speaking are conversations with friends, conversations with tourists, and oral presentations; for the writing skill: electronic mail and class notes; for the listening skill: movies, TV Cable and the teacher; for the reading skill: computer programs and video games and Internet web pages. (See Table 3)

Table 3

Important Resources that Facilitate Listening, Speaking, Reading and Writing according to the Urban High Schools in Costa Rica

\begin{tabular}{|c|c|}
\hline Resources & "Highest Scores \\
\hline Conversations with friends. & $\ldots 76.94 \%$ \\
\hline Conversations with tourists & $55.88 \%$ \\
\hline Oral presentations ................ & $.50 .00 \%$ \\
\hline Electronic mail & $69.32 \%$ \\
\hline Class notes ....... & .... $54.47 \%$ \\
\hline Movies & $68.51 \%$ \\
\hline TV Cable... & $66.30 \%$ \\
\hline Computer programs and video games & $65.57 \%$ \\
\hline
\end{tabular}


As rural high school students, urban ones chose the speaking skill as the most important one for getting a job, talking to tourists, studying abroad, and for communicating with people from other countries and cultures.

Both rural and urban students agreed that that the most important resources for practicing and learning English are conversations with tourists, computer programs, movies and class notes. (See Table 4)

Table 4

Rural and Urban High Schools-Agreement on Importance of Resources

\begin{tabular}{|c|c|c|}
\hline Resources & Rural Students & Urban Students \\
\hline Conversations with tourists & $.53 .81 \%$ & $.55 .88 \%$ \\
\hline Computer programs / video games & s $61.32 \%$ & $65.57 \%$ \\
\hline 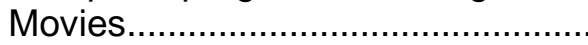 & $\ldots 63.13 \% \ldots \ldots$ & .......68.51 \% \\
\hline Class Notes & $53.69 \%$ & $54.47 \%$ \\
\hline
\end{tabular}

\subsubsection{Discussion of the Results}

This survey on student's perceptions about the four skills complements CyberL@b's design and implementation. It was important to find out if high school students believed that the four skills were necessary skills in EFL. Indeed, they do. Students' feedback on how important the four skills were for them enriched this digital platform as follows:

a) The activities were designed as interactive web-based type of materials.

b) The warm-ups, pre- and post activities, and the "your turn's" focus on the speaking skill.

c) Supplementary activities like culture notes, role-plays, and information-gaps were added to have students work on additional conversations to enhance the speaking skill.

d) The final projects serve as a "wrap up" of the entire unit by having students work in groups and do listening, speaking, reading, and writing meaningful tasks to accomplish the demanding objectives of each project.

e) The section "Surf the Web" allows learners become autonomous as they selfdirect their own learning though a resource which they said were motivational for acquiring the main language skills. 
It is evident that both rural and urban students consider speaking the most important skill for communicative and job purposes. However, they are also clear on the fact that "speaking cannot work by itself basically because people use all four skills on natural communication". The results of this qualitative study also tell us that students do not want traditional methodologies any more. They, as individuals, are seeking for the latest trends, like technology, as a means that could motivate them to want to learn English. With this survey, the researchers have tried to hear students' voices and provide them with an answer that suits their needs: promote communication through Web-based CALL and the integration of the four skills.

\section{Conclusion}

Computer-Assisted Language Learning is a powerful approach with much to offer to the field of English Language Teaching. When students engage in authentic activities that are relevant to their needs, they become more-autonomous and self-directed in their learning. This allows teachers to adopt more learner-centered methodology for language teaching. The CyberL@b resources and curriculum offer a variety of self-directed and collaborative activities that lead foreign language learners towards accuracy and fluency in meaningful contexts. Learners are engaged in authentic social contexts and involved in the integration of the four language skills: listening, speaking, reading and writing. As learners immerse themselves in this digital environment they are learning a foreign language in a proactive way that encourages active communication and self-expression in the foreign language. There is less teacher-talk, and more student-talk though Web-based CALL, allowing learners more control and ability to personalize their own learning. They are also learning critical competencies and attitudes in the use of technology that will make them more competitive in a global information society.

An integrated skills approach exposes language learners to meaningful learning and challenges them to interact naturally in English. Learners rapidly gain a true picture of the richness and complexity of the English language as it is used for communication. Integrating the four skills also promotes the learning of real content and facilitates the combination of both topic-based and task-based approaches in language teaching, a pedagogical alliance which is unique in CyberL@b.

The CyberL@b resources and curriculum are responsive to emerging trends in teaching in Costa Rica where technology becomes a key element in teaching and learning of a foreign language. Its platform embraces the following features: interactive digital materials, 
autonomous learning, different teaching styles, and the integration of grammar-based, skillbased, task-based, project-based, and collaborative-based trends in EFL.

As we continue to refine CyberL@b and conduct research on the needs in the rapidly evolving culture of our schools, we are considering further enhancements to resources and instructional methods. The teacher and students will indeed recognize the importance of authentic learning activities through web-based materials. Added to this, both students and teachers will appreciate the opportunity to interact in English with the help of other resources in meaningful ways and at the same time, value the connection of language and culture in comparable English speaking schools.

For this reason, the feasibility of a variety of approaches and technical strategies for establishing sister cities school in English speaking countries is currently being investigated. The schools will be connected on the basis of such factors as common demography, geography, culture, economy and employment. This approach will integrate the CyberL@b activities and curriculum with real-time interactive video (such as MS Net Meeting and Video iChat from Apple) allowing the students to interact directly in their sister school.

\section{References}

Aust, Ronald \& Isaacson, Ronald. (2005). Designing and Evaluating User Interfaces for eLearning. In G. Richards (Ed.), Proceedings of World Conference on E-Learning in Corporate, Government, Healthcare, and Higher Education Chesapeake (pp. 1195-2104). VA: AACE.

Aust, Ronald, Newberry, Brian, \& OBrien, John. (2005) Learning generation: fostering innovation with tomorrow's teachers and technology. Journal of Technology and Teacher Education. 13 (2), 167 - 195.

Campos, Ana Isabel et. al. (2003). Programa de Inglés - III Ciclo. Retrieved from the World Wide Web, August 19, 2006 http://www.mep.go.cr/programasestudio2005.html

Duhaney, Devon (2001). Teacher education: Preparing teachers to integrate technology. International Journal of Instructional Media, 28, 23-24.

Egbert, Joy \& Hanson-Smith, Elizabeth. (1999). CALL environments: Research, practice and critical issues. Alexandria, VA: Teachers of English to Speakers of other Languages.

Egbert, Joy, Chao, Chin-chi \& E. Hanson-Smith, Elizabeth. (1999). Computer-enhanced Language learning Environments: An overview. In J. Egbert \& E. Hanson-Smith (Eds.), CALL environments: Research, practice and critical issues (pp 1-13). Alexandria, VA: Teachers of English to Speakers of other Languages. 
Levy, Mike. (1990). Towards a theory of CALL. CAELL Journal, 1 (4), 5-7.

Qiming Su, William. (2006). Web-based Computer Assisted Language Learning. Retrieved from the World Wide Web, April 7, 2006. http://infosys.massey.ac.nz/ kinshuk/papers/deanz2002 call.pdf

Robert, Jackson (2006). Issues and resources for Web-based learning. Retrieved from the World Wide Web, April 7, 2006. http://www.knowledgeability.biz/weblearning/\#An200verview\%20of\%20WebBased\%20Learning

Shneiderman, Ben. (1998) Designing the user interface: strategies for effective human computer interaction. Reading, MA: Addison Wesley Longman. 